\title{
Maternal and Neonatal Exposure to Environmental Tobacco Smoke Targets Pro-Inflammatory Genes in Neonatal Arteries
}

\author{
Amparo C. Villablanca • Kent E. Pinkerton • \\ John C. Rutledge
}

Received: 14 June 2010 /Accepted: 20 September 2010 / Published online: 2 October 2010

(C) The Author(s) 2010. This article is published with open access at Springerlink.com

\begin{abstract}
Maternal mainstream tobacco smoking is known to have adverse outcomes on fetal respiratory function; however, no data is currently available on the effects of passive exposure to tobacco smoking and environmental tobacco smoke (ETS) on fetal systemic arterial structure and function. Eight pregnant rhesus macaque monkeys were studied at the California Regional Primate Research Center breeding colony. The estimated gestational age for each dam was established by sonography performed before gestational day 40. Two inhalation chambers were used, each with an air capacity of $3.5 \mathrm{~m}^{3}$, and each housed two dams. Aged and diluted sidestream smoke was used as a surrogate for ETS. Exposure to ETS $\left(1 \mathrm{mg} / \mathrm{m}^{3}\right)$ occurred for $6 \mathrm{~h} /$ day, 5 days/ week, beginning on gestational day 100. All dams were allowed to give birth spontaneously and then ETS exposure continued 70-80 days postnatally with the chamber containing both the mother and infant. Carotid arteries from four control (C) and four ETS-treated newborns were analyzed for mRNA by gene macroarray and for protein by Western blotting. A total of 588 cardiovascular genes were studied. Four genes were upregulated by ETS compared to C, and nine genes were downregulated ( $\geq 2$-fold change). Three genes were selected for further study. Following ETS
\end{abstract}

A. C. Villablanca $\cdot$ J. C. Rutledge

Department of Internal Medicine, University of California,

Davis, CA, USA

K. E. Pinkerton

Center for Health and the Environment, University of California,

Davis, CA, USA

\section{A. C. Villablanca $(\bowtie)$}

Division of Cardiovascular Medicine, University of California,

One Shields Avenue, TB 172,

Davis, CA 95616-8636, USA

e-mail: avillablanca@ucdavis.edu exposure, neonatal carotid arteries of non-human primates manifested evidence of inflammation with increased gene and protein expression of LFA-1 and RANTES, proteins that are recognized to be important in vascular adhesion and inflammation, and downregulation of expression for the receptor for VEGF, which has a key role in angiogenesis. Prenatal and postnatal exposure to ETS increases expression of pro-inflammatory genes and may be responsible for early arterial vascular remodeling that is predisposing to a subsequent vascular disease.

Keywords Smoking · Vascular · Inflammation · Genes · Macroarray $\cdot$ Monkey $\cdot$ Neonate $\cdot$ Angiogenesis

\section{Introduction}

Tobacco smoking is a major cause of morbidity and mortality in the U.S. and an increasingly important cause of death and disability worldwide. Further, maternal mainstream tobacco smoking is known to have multiple adverse fetal outcomes, including reduced fetal respiratory function [1-12]. Exposure to tobacco smoking, either mainstream or environmental tobacco smoke (ETS), is a major modifiable cardiovascular risk factor known to exert deleterious effects on fetal systemic arterial structure and function $[4,13,14]$. This is an important area of research because arterial disease, specifically atherosclerotic cardiovascular disease, is the leading cause of morbidity and mortality in adults, which develops over decades with its onset early in life. Multiple reports have now documented that early and intermediate stage atheroma occurs in children and teenagers [14-19]. Thus, it is plausible that early injury to fetal arteries in the in utero environment can predispose to arterial disease in adulthood. 
Exposure to ETS or passive smoking is increasingly appreciated to have major adverse health effects and to result in a pro-inflammatory state $[20,21]$. Our previous work showed that ETS increases endothelial layer permeability, low-density lipoprotein accumulation, and stiffening in the artery wall $[21,22]$. Thus, work from a number of laboratories, including our own, indicate that exposure to either mainstream tobacco smoke or ETS acutely injures the artery wall and predisposes to chronic inflammation; however, no studies have yet been conducted that examine the effects of ETS exposure of the mother and neonate on the inflammatory status of the vasculature of the neonate.

Atherosclerosis has its origins in the arterial subendothelium and is an inflammatory state characterized by arterial injury $[23,24]$. The vascular pathology is characterized by inflammation involving a number of cells, including blood-borne monocytes [25]. Monocyte recruitment is promoted by a several factors, including cellular adhesion molecules, such as vascular cell adhesion molecule-1 resulting in monocyte transmigration to the subendothelial space. In the subendothelial space, "foam cells" or lipid-filled macrophages are formed [26]. The interaction of macrophages and lipids play a central role in the development of atherosclerosis through foam cell formation and via the induction of numerous cytokines, chemokines, such as RANTES [27], and growth factors, including vascular endothelial growth factor (VEGF) [28]. In this study, we hypothesized that chronic maternal, fetal, and neonatal exposure to ETS increases molecular markers and mediators of arterial injury and inflammation in fetal arteries.

\section{Materials and Methods}

Animals and Smoke Exposure Protocols All studies were carried out in accordance with the declaration of Helsinki and with the Guide for the Care and Use of Laboratory Animals as adopted and promulgated by the National Institutes of Health (http://oacu.od.nih.gov/regs/guide/ guide.pdf). Eight pregnant Rhesus macaque monkeys were obtained from the California National Primate Research Center breeding colony. Estimated gestational age for each dam was established by sonography performed before gestational day 40. Animals were selected based on a history of successful vaginal delivery and previous infant rearing experience with estimated delivery dates separated by approximately 1 week per animal to facilitate experimental procedures.

Two inhalation chambers were used, each with an air capacity of $3.5 \mathrm{~m}^{3}$, and each housed two dams. Aged and diluted sidestream smoke was used as a surrogate control for ETS. Standardized 1R4F research cigarettes were smoked simultaneously with a single puff volume of $35 \mathrm{ml}$ per cigarette and a duration of $2 \mathrm{~s}$, once per min. ETS was generated by a smoke exposure system (Teague Enterprises, Davis, CA) using IR4F conditioned cigarettes from the Tobacco and Health Research Institute of the University of Kentucky. Sidestream smoke from the smoldering end of each cigarette was collected into a conditioning chamber where it was aged over a period of approximately 2 to $3 \mathrm{~min}$ while being diluted with filtered air and then further diluted as it passed into the exposure chambers to produce total suspended particulate concentrations of $1.0 \mathrm{mg} / \mathrm{m}^{3}, 4-5 \mathrm{ppm}$ carbon monoxide and $200-300 \mu \mathrm{g} / \mathrm{m}^{3}$ nicotine. This level of exposure is highly reminiscent of ETS concentrations found in homes or the workplace where smoking is permitted. The exposure chambers were stainless steel and glass Hinners type and $4.2 \mathrm{~m}^{3}$ in size. Each chamber has an air capacity of $3.5 \mathrm{~m}^{3}$. Airflow through the system was set for 15 changes per hour.

Exposure to ETS $\left(1 \mathrm{mg} / \mathrm{m}^{3}\right)$ occurred for $6 \mathrm{~h} /$ day, 5 days/ week, beginning on gestational day 100. All dams were allowed to give birth spontaneously (five male and three female infants born), and then ETS or sidestream control exposure continued for 70-80 days postnatally for the four experimental and four control animals, respectively with the chamber containing both the mother and infant. Infants were then sacrificed (mean age, 72 days) and bilateral carotid arteries dissected and cleansed of adventitial fat. Carotid arteries from four control and four ETS-treated newborns (mean weight of animals at sacrifice, $0.84 \mathrm{~kg}$ ) were then analyzed for mRNA by gene macroarray and for protein by Western blotting. Tissues were flash-frozen and stored at $-80^{\circ} \mathrm{C}$ until assayed.

RNA Isolation All procedures were performed under RNAsefree conditions. RNA was isolated from the carotid artery samples from the neonatal monkeys using Tri Reagent (Molecular Research Center, Inc., Cincinnati, OH) following tissue disruption with a mortar and pestle and subsequent use of a tissue hand-held glass homogenizer (Kontes). Total RNA was extracted using chloroform or 1-Bromo-3-Chloropropane (BCP) Phase Separation Reagent (Molecular Research). Each carotid (25-33 mg tissue) yielded approximately $2.0-3.3 \mathrm{mg}$ of total RNA. Following extraction, RNA was treated with DNAse using Clontech DNAse-1 per the manufacturer's instructions (MessageClean DNAse-1; GenHunter Corporation, Nashville, TN). Total RNA from the control and ETSexposed aortas were used to prepare two radioactive probes for array hybridization.

Probe Preparation and Array Hybridization The Atlas Human Cardiovascular cDNA Expression Array Kit and reagents (Clontech, Palo Alto, CA) were used for these studies. The array contains duplicate copies of 588 
cardiovascular genes and multiple control and housekeeping genes (http://www.clontech.com). The cardiovascular genes consist of six major categories as follows: (1) cell cycle regulators/intermediate filament markers, (2) apoptosis/oncogenes/tumor suppressors, (3) DNA damage/repair and cell development, (4) cell adhesion/mobility and angiogenesis, (5) cell-cell interactions, and (6) growth factors/cytokines.

The ${ }^{33} \mathrm{P}$-labeled cDNA probes were synthesized by reverse transcription of total RNA from filtered air (control) and environmental tobacco smoke-exposed monkey carotids using a gene-specific primer mix $(1 \mu \mathrm{l}, 0.2 \mu \mathrm{M}$ of each primer) and annealed to $2.13 \mu \mathrm{g}$ of total RNA. The mixture was heated for $2 \mathrm{~min}$ at $70^{\circ} \mathrm{C}$ in a thermal cycler (Perkin Elmer, Waltham, MA), then incubated for $2 \mathrm{~min}$ at $50^{\circ} \mathrm{C}$. First strand cDNA synthesis was initiated by mixing the annealed primer with the RNA and master mix [containing $4 \mu \mathrm{l}$ of $5 \mathrm{X}$ reaction buffer $(250 \mathrm{mM}$ Tris $-\mathrm{HCl}, \mathrm{pH} 8.3$, $375 \mathrm{mM} \mathrm{KCl}, 15 \mathrm{mM} \mathrm{MgCl} 2), 2 \mu \mathrm{l}$ of dNTP mix $(0.5 \mathrm{mM}$ of each dGTP, dCTP, and dTTP), $5 \mu$ of $\left[\alpha^{-33} \mathrm{P}\right] \mathrm{dATP}$ (3,000 Ci/mmol), (10 mCi/ml; NEN, Boston, MA.), $1 \mu \mathrm{l}$ DTT $(100 \mathrm{mM})$, and $2 \mu \mathrm{l}$ of MMLV reverse transcriptase $(50 \mathrm{U} / \mu \mathrm{l})]$. The reaction was incubated in a thermal cycler (Perkin Elmer) at $50^{\circ} \mathrm{C}$ for $25 \mathrm{~min}$ and stopped by addition of $1 \mu \mathrm{l}$ termination mix [0.1 M EDTA (pH 8.0), $1 \mathrm{mg} / \mathrm{ml}$ glycogen]. The labeled cDNA probe was purified from unincorporated ${ }^{33} \mathrm{P}$-labeled nucleotides by gel filtration chromatography using a 1-ml NucleoSpin extraction spin column (Clontech) per the manufacturer's instructions. The purified-labeled cDNA probes (approximately $1 \times 10^{6} \mathrm{cpm}$ for control and ETS-exposed monkey carotid) were utilized for macroarray hybridization.

Macroarray Hybridization The probes were prepared for hybridization by adding $10 \mathrm{X}$ denaturing solution (1 M $\mathrm{NaOH}, 10 \mathrm{mM}$ EDTA) to the entire pool of labeled probe and incubated at $68^{\circ} \mathrm{C}$ for $20 \mathrm{~min}$. Cot-1 DNA and $2 \mathrm{X}$ neutralizing solution (1 M NaH2PO4, $\mathrm{pH} 7.0)$ was added to the denatured probe and incubated at $68^{\circ} \mathrm{C}$ for $10 \mathrm{~min}$. The labeled probe solution was mixed together with preheated ExpressHyb hybridization solution. Each of the two duplicate Atlas Human Cardiovascular Array membranes were pre-wet with de-ionized $\mathrm{H}_{2} \mathrm{O}$ and prehybridized for $30 \mathrm{~min}$ at $68^{\circ} \mathrm{C}$. Under continuous agitation, the array membranes were hybridized overnight at $68^{\circ} \mathrm{C}$, washed three times with $2 \mathrm{X}$ SSC, $1 \%$ sodium dodecyl sulfate (SDS) at $68^{\circ} \mathrm{C}$, washed twice with $0.1 \mathrm{X}$ SSC, $0.5 \%$ SDS for $30 \mathrm{~min}$ at $68^{\circ} \mathrm{C}$, and then washed for 5 min with $2 \mathrm{X} \mathrm{SSC}$ at room temperature (RT).

Signal Detection and Image Analysis The washed membranes were sealed in plastic wrap and exposed directly to a storage phosphor screen (Molecular Dynamics, Sunnyvale,
CA) for 8 days. The screen was scanned using Storm 840 in storage phosphor mode. Signal intensity was quantified using an ImageQuant software for identification of differentially expressed genes. In ImageQuant, grid objects were created and used for simultaneous quantitation of all duplicate spots on each array. Grids of seven columns by 14 rows were used to analyze the six main gene groupings on the macroarrays. Separate grids were created for housekeeping gene spots and for determining background (unspotted, unhybridized areas of the membrane), which was subtracted from volume densitometry values for the grid cells. Twenty-three kilo Daltons highly basic protein and $60 \mathrm{~S}$ ribosomal protein L13A (aka RPL 13A) housekeeping gene values were used for normalization based on the equality of signal strength between both arrays. This normalization scheme was further validated by the equality in normalized expression of many of the common genes on both arrays.

Real-Time RT-PCR-Based Confirmation of Differential Gene Expression To further confirm differential mRNA expression of the genes identified to be regulated by ETS in the macroarray analysis, we performed real-time polymerase chain reaction (PCR) utilizing two additional ETSexposed and control monkey aortas. Thus, for these experiments, a total of six aortas were studied for ETSexposed and control neonatal monkeys, respectively. The aortas were from the same experimental animal cohort as described earlier in the "Materials and Methods" section. Briefly, total RNA from the ETS and control aortas was treated with DNAse (MessageClean DNAse-I; GenHunter) and cDNA generated by reverse transcriptase (RT)-PCR. A mixture of oligo (dT) oligodeoxynucleotide primers (T1218) and random hexamer primers were used for these studies following the protocol for SuperScript RNAse HReverse Transcriptase (GibcoBRL, Rockville, MD). Realtime detection of PCR was performed using the GeneAmp 5700 Sequence Detection System (Applied Biosystems, Foster City, CA) according to the manufacturer's instructions. The same gene-specific primers used for semiquantitative PCR analysis were used for real-time PCR detection of the genes of interest. Equal amounts of duplicate or triplicate sample cDNA were amplified with the SYBR Green I Master Mix (Applied Biosystems). The thermal cycling parameters were thermal activation for $10 \mathrm{~min}$ at $95^{\circ} \mathrm{C}$ followed by 40 cycles of PCR (melting for $15 \mathrm{~s}$ at $95^{\circ}$ $\mathrm{C}$ and annealing extension for $1 \mathrm{~min}$ at $60^{\circ} \mathrm{C}$ ). A standard curve was constructed using a template dilution series $(1: 10,1: 20,1: 40,1: 80$, and 1:160) of total RNA from monkey aorta. A "no template" negative control was included with each PCR. Amplification efficiency for each of the genes of interest was then validated and normalized against glyceraldehyde-3-phosphate dehydrogenase 
(GAPDH). In order to compare the relative expression of the various genes, data was expressed as the normalized densitometry ratio of ETS to control aortas.

Western Blotting Protein was prepared from monkey carotid sections from filtered air (control) and ETS-exposed monkeys using Tri Reagent (Molecular Research Center, Inc., Cincinnati, $\mathrm{OH}$ ) or NE-PER Nuclear and Cytoplasmic Extraction Reagents (Pierce, Rockford, IL), and mammalian Protease Inhibitor Cocktail (Sigma, Saint Louis, MO) per the manufacturer's protocol. Protein quantity was assayed by detergentcompatible DC protein assay (BioRad, Hercules, CA). Ready gels for SDS-PAGE electrophoresis (BioRad) were used with the appropriate gel concentration for the size of the protein of interest (loading $\sim 44 \mathrm{mg}$ of protein per lane). Kaleidoscope molecular weight markers (BioRad) were loaded in one or two lanes of the gels for size markers. The gels were electrophoresed at $60 \mathrm{~V}$ for 15-30 min, followed by $60-90 \mathrm{~min}$ at $120 \mathrm{~V}$ depending on the speed of migration. After electrophoresis, electroblotting proceeded for $1 \mathrm{~h}$ at $100 \mathrm{~V}$ on ice.

The blot was blocked in $10 \% \mathrm{w} / v$ non-fat dry milk TrisBuffered Saline Tween-20 (TBST) solution overnight at $4^{\circ} \mathrm{C}$. The nitrocellulose membrane was washed three times with TBS, $0.05 \%$ Tween. The primary antibody was diluted in TBST to concentrations previously determined or according to manufacturer's recommendations and incubated for $\sim 1 \mathrm{~h}$ at RT. The secondary antibody was diluted in TBST and incubated for $\sim 1 \mathrm{~h}$ at RT. The nitrocellulose was washed two times with TBST. Electrochemiluminescence (ECL) Detection Reagents (Amersham Pharmacia Biotech, Buckinghamshire, England) horseradish peroxidase (HRP)-based detection was used. Blots were wrapped in saran and exposed to autoradiograph film (Kodak Biomax, Rochester, NY). Densitometry was performed on a Kodak 1D gel imaging system. Some blots were stripped with Restore Western Blot Stripping Buffer (Pierce) and re-probed with mouse anti-actin or a different primary antibody than that stripped, followed by a secondary antibody and ECL detection as described. Details of the antibodies used and protein products of the genes studied (see "Results") are as follows:RANTES (8 kDa protein) - primary antibody goat polyclonal anti-RANTES (Santa Cruz Biotech, Santa Cruz, CA; 1:1000 dilution) and secondary antibody bovine anti-goat IgG HRP (Santa Cruz Biotech; 1:10,000-1:30,000 dilution); VEGFR2 [flk-1] (130 kDa protein) - primary antibody rabbit polyclonal antineuropilin-1 (Oncogene Research Products, La Jolla, CA; 1:100-1:200 dilution) and secondary antibody goat antirabbit IgG HRP (BioRad; 1:15,000 dilution), as well as primary antibody goat polyclonal anti-neuropilin-2 (Santa Cruz Biotech; 1:100 dilution) and secondary antibody bovine anti-goat Ig G HRP (Santa Cruz Biotech; 1:10,000-1:30,000 dilution); LFA-1 [integrin alpha L] (180 kDa protein)primary antibody goal polyclonal anti-LFA1 (Santa Cruz
Biotech; 1:100 dilution) and secondary antibody bovine antigoat IgG HRP (Santa Cruz Biotech; 1:10,000-1:30,000 dilution); actin control (41 kDa protein) - primary antibody mouse monoclonal anti-actin (Sigma; 1:1,000 dilution) and secondary antibody goat anti-mouse IgG HRP (BioRad; 1:15,000 dilution).

Data Analysis Densitometry values were obtained for each array cDNA from ETS-treated and control samples, and quantification of spots on arrays from ETS-treated and control (sidestream air) aortas was performed. In order to allow the array products to be quantified comparatively, arrays were also spotted with two housekeeping genes. This permitted the spot densitometry values of the ETS-treated and control array signals to be normalized to the housekeeping signals and to calculate normalized densitometry ratios. Background signal was subtracted from the control and ETS spots prior to analysis. Normalized ratio data from the arrays were then evaluated for differential expression (i.e., greater or less than a 2-fold difference in expression in the ETS-treated versus the control samples). All arrays were spotted in duplicate. Four aortas each were used for the ETS-treated and the control arrays.

Quantification of PCR products was performed in a similar fashion. PCR amplifications were conducted with GAPDH in order to permit normalization of signals to GAPDH and to account for any minor variations in DNA loading in the PCR product signals. Normalized ratio data from PCR reactions were then evaluated for differential expression (i.e., greater or less than a 2-fold difference in expression in the ETS-treated versus the control samples). All PCR reactions were performed in duplicate. Six aortas each were used for the ETS-treated and the control PCRs. Normalized data from arrays and PCR were expressed as relative fold change in expression for ETS compared to control-treated aortas.

Western blot experiments were performed in triplicate or greater, and data expressed as mean $+/-$ standard error of the mean (SEM) for net densitometry values for the four control and the four ETS-treated aortas. Means +/- SEM and mean fold change in protein expression in the ETStreated and control protein products was then calculated. Statistical significance was at the $p<0.05$ level.

For the array, PCR, and Western assays, the calculated fold-change differences between the ETS-treated and control samples were based on the mean values of the four subjects in each of the control and study groups.

\section{Results}

Up- and Downregulated Aortic Genes by Macroarray Analysis Macroarray analysis was performed on the neonatal carotid arteries from animals whose mothers were exposed to ETS or filtered air (control). Five hundred eighty-eight array 
Table 1 Summary of differential gene expression by ETS utilizing the atlas human cardiovascular cDNA expression array

\begin{tabular}{|c|c|c|c|}
\hline & $\begin{array}{l}\text { Array coordinate } \\
\text { (block, row, column) }\end{array}$ & Gene name (Gene Functional Classification Category) & $\begin{array}{l}\text { Fold-change } \\
\text { expression }^{\mathrm{a}}\end{array}$ \\
\hline \multirow[t]{4}{*}{$\begin{array}{l}\text { Upregulated } \\
\text { genes }\end{array}$} & Ah3 & $\begin{array}{l}\text { T cell-specific rantes protein precursor; sis delta; small inducible cytokine A5 } \\
\text { (growth factor, cytokine and chemokines) }\end{array}$ & 19.7 \\
\hline & $\mathrm{Bg} 2$ & Adipocyte fatty acid-binding protein 4 (trafficking and targeting proteins) & 2.8 \\
\hline & Bj6 & Lumican precursor (extracellular matrix proteins) & 5 \\
\hline & $\mathrm{Cn} 4$ & $\begin{array}{l}\text { Leukocyte adhesion glycoprotein LFA-1 alpha subunit precursor; leukocyte } \\
\text { function-associated molecule } 1 \text { alpha chain; CDIIA antigen; integrin alpha } L \\
\text { (cell-cell adhesion receptors) }\end{array}$ & 8.5 \\
\hline \multirow[t]{9}{*}{$\begin{array}{l}\text { Downregulated } \\
\text { genes }\end{array}$} & Aa7 & $\begin{array}{l}\text { Vascular endothelial cell growth factor } 165 \text { receptor [VEGF-R2] (growth factor } \\
\text { and chemokine receptors) }\end{array}$ & -2.8 \\
\hline & Bk5 & Caveolin 3 (GTP/GDP Exchangers and GTPase activity modulators) & -2 \\
\hline & $\mathrm{Cg} 2$ & $\begin{array}{l}\text { GAP junction alpha-1 protein (cell-cell adhesion receptors and other membrane } \\
\text { channels and transporters) }\end{array}$ & -2 \\
\hline & $\mathrm{Cl} 3$ & Integrin alpha 8 (cell-cell adhesion receptors) & -2.2 \\
\hline & $\mathrm{Cm} 5$ & Procollagen 1 alpha 2 subunit precursor (extracellular matrix proteins) & -2.9 \\
\hline & Dj1 & Profilin 1 (cytoskeleton and motility proteins) & -3 \\
\hline & Dm3 & $\begin{array}{l}\text { Tissue inhibitor of metalloproteinase } 1 \text { precursor [TIMP-1] (extracellular matrix } \\
\text { proteins and protease inhibitors) }\end{array}$ & -2.8 \\
\hline & Ff1 & $\begin{array}{l}\mathrm{N} \text {-acetylglucosamine-6-sulfatase precursor; glucosamine-6-sulfatase (complex } \\
\text { carbohydrate metabolism) }\end{array}$ & -4.1 \\
\hline & $\mathrm{Fg} 5$ & Natriuretic peptide precursor B (hormones) & -4.2 \\
\hline
\end{tabular}

\footnotetext{
${ }^{a}$ Upregulated and downregulated refer to fold change in expression level for ETS vs control. Italics denote genes selected for further study based on their expression level and/or vascular relevance. See text for details
}

genes and nine housekeeping and control (filtered air) genes were spotted in duplicate. A complete set of the macroarray data for the 588 genes analyzed was submitted to the Center for Information Biology Gene Expression Database (CIBEX Accession: CBX26). Compared to the control, ETS upregulated genes for RANTES and LFA-1 corresponded to cell coordinate (block, row, column) Ah3 and $\mathrm{Cn} 4$, respectively. ETS downregulation of VEGFR2 corresponded to cell coordinate Aa7. Genes of interest were identified by a greater than 2-fold increase or decrease in expression relative to the mean housekeeping gene expression level. This resulted in the identification of four genes upregulated by ETS compared to the control and nine genes downregulated by ETS compared to the control. A summary of the differential gene expression by ETS utilizing the Atlas human cardiovascular cDNA expression array and their functional categorization is summarized in Table 1.

Three genes of interest were identified for further study based on the level of expression and/or their physiological/ functional significance in the vasculature as follows: (1) $\mathrm{T}$ cell-specific rantes protein (RANTES) precursor, (2) leukocyte adhesion glycoprotein (LFA-1; CD11a/CD18) alpha subunit, and (3) vascular endothelial cell growth factor receptor (VEGFR2; FLk1). RANTES and LFA-1 were upregulated by ETS relative to filtered air control with expression levels that were 19.7 and 8.5 greater than the control, respectively. VEGFR2 was downregulated (2.8fold less) by ETS exposure relative to the control (Table 1).
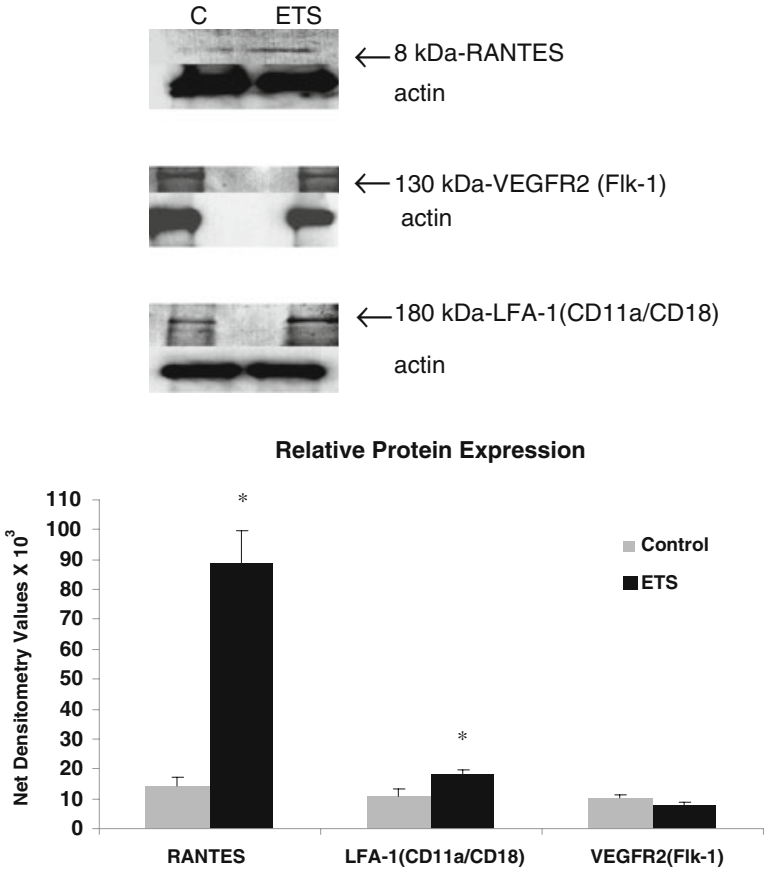

Fig. 1 Western blot analysis for differentially expressed genes in monkey carotids in response to environmental tobacco smoke (ETS) compared to control $(C)$. The blots demonstrate upregulation of protein expression for RANTES and LFA-1 by ETS compared to control $(C)$ 
Table 2 Comparison of gene macrochip array, real-time PCR, and Western blot protein expression for the three genes of interest in this study

Fold change in expression for ETS vs filtered air control

\begin{tabular}{lccc}
\hline & Gene array & Real-time PCR & Protein \\
\hline RANTES & +19.7 & $\mathrm{n} / \mathrm{a}$ & +6.2 \\
LFA-1 (CD11a/CD18) & +8.5 & +12.2 & +1.7 \\
VEGFR-2 (Flk-1) & -2.8 & -1.7 & -0.7 \\
\hline
\end{tabular}

ETS environmental tobacco smoke, $C$ control (filtered air)

Differential Expression of Genes of Interest We performed RT-PCR to confirm differential expression for the genes of interest. The expression ratios for ETS were 12.2-fold greater than the control for LFA-1 and 1.7-fold less than the control for VEGFR2. Despite repeated attempts, however, we were unable to verify the differential expression for RANTES by real-time PCR despite there being a clear increase in gene expression for this gene by macroarray and in protein expression by Western blotting following ETS exposure (see below).

Next, confirmation of functional expression of the three genes was sought by determining protein expression using Western blotting (Fig. 1). In these studies, protein expression for RANTES and LFA-1 was increased for ETS compared to control arteries by 6.2- and 1.7-fold, respectively. These findings were in concert with the previously observed upregulation in gene expression noted by macroarray analysis for these genes following ETS exposure. In contrast, protein expression for VEGFR2 was decreased 0.7-fold by ETS exposure compared to filtered air exposure, in concert with downregulation in gene expression for this gene by both macroarray and real-time PCR. A summary of gene and protein expression level changes for the three genes of interest is provided in Table 2.

\section{Discussion}

This study shows that inhalation of ETS by the mother alters neonatal gene and protein expression in systemic arteries. How ETS has these effects on fetal arteries is not clear. The injury to fetal arteries could occur in a number of ways, including reduced placental blood flow, activation of platelets and leukocytes, and vascular wall inflammation.

Two genes were upregulated by ETS and are of particular interest in this study: (1) RANTES (regulated on activation of normal $\mathrm{T}$ cell expressed and secreted) and (2) LFA-1 (a $\beta 2$ integrin leukocyte function antigen, also known as $\mathrm{CD} 11 \mathrm{a} / \mathrm{CD} 18$ ). These genes are proinflammatory. RANTES is a small inducible cytokine that functions as a chemoattractant and an activating cytokine for monocyte cell recruitment to atherosclerotic plaque [27], a chemokine for inflammatory cells [22] and mediator of inflammation [29-31]. It is also implicated in atherosclerotic lesion formation as it is a macrophage inflammatory protein [30] and is secreted by vascular endothelial cells [32]. RANTES is strongly induced in response to cellular insult. LFA-1 is a surface glycoprotein and cell adhesion molecule that plays a key role in cell trafficking and cell-to-cell contact, including leukocyte/monocyte adhesion to the endothelium, one of the early events in atherogenesis and has a role in vascular injury, as reviewed by Galkina and Ley [33]. LFA-1 also has an important role in the pathophysiology of inflammation and immunity [34, 35]. Thus, the coordinated upregulation by ETS of expression for plasma membrane glycoproteins involved in leukocyte adhesion, such as LFA-1, and chemoattractants, such as RANTES, provide a molecular mechanism for ETS-mediated vascular injury in neonatal arteries.

These experiments also demonstrated a downregulation of gene expression for vascular endothelial growth factor receptor (VEGFR) by ETS exposure. VEGF is derived from vascular smooth muscle cells and fibroblasts, acts on endothelium, and is a key regulator of physiological and pathological angiogenesis (tumor angiogenesis). VEGF is found in human coronary vessels where it participates in atherosclerosis and plaque growth and angiogenesis [36, 37]. VEGF also participates in revascularization in response to injury and is mitogenic for vascular endothelial cells [38, 39]. Two VEGFR genes are known, the VEGFR-1 (flt-1) and VEGFR-2 (KDR/flk-1), which are genes that encode VEGF-specific tyrosine kinase. In this study, downregulation of VEGFR2 gene expression by ETS was not accompanied by substantial downregulation of protein expression ( 7\% downregulation), suggesting gene regulation by ETS at the translational level. Translation is the target of multiple regulatory proteins. Translational repression of mRNA is consistent with reduced or absent translation known as translational silencing. There are examples of translational silencing of a complex of inflammatory RNAs that share similar co-regulatory factors. One example is the interferon-gamma-activated translational inhibitor (GATI) complex known to be involved in translational silencing. Inflammatory genes are known to be a target of this pathway. Although no prior negative translational regulation had been previously described for VEGF, this gene has recently been reported to be a target of the GATI pathway [40]. Since the endothelial cell-specific VEGF and its cellular receptors Flt-1 and Flk-1 have been implicated in the formation of the embryonic vasculature, this mechanism of translational silencing by ETS of an angiogenesis gene may be of potential importance in local angiogenic responses and in regulating translational inhibition of angionesis. 
This study has limitations. A major question posed is whether arterial injury that occurs in the pre- and postnatal period has long-term adverse outcomes. There is some precedence for this in asthma where rodent studies have shown that perinatal exposure to tobacco smoke early in life increased airway responsiveness later [6]; however, our studies were not designed to address these long-term questions. An additional limitation relates to the lack of success in amplifying the RANTES gene for real-time PCR confirmation of the macroarray findings. Further attempts were limited by lack of availability of additional tissue; however, we are confident of our findings given concomitant upregulation of gene expression by macroarray and protein expression by Western blotting for this gene. Atherosclerosis lesion development was not directly studied because the animals were not hyperlipidemic or cholesterol-fed, and they were of a very young age (70-80 days). In addition, biomarkers of exposure were not analyzed because the primary focus of the study was the molecular changes in the carotid arteries; however, a recent publication by a co-author of the present study [41] utilized a similar system to demonstrate biomarkers of ETS exposure are present; following 1 year of postnatal exposure, non-human primates' aortas were found to have increased vascular oxidative stress (protein carbonyls and SOD) and mitochondrial dysfunction/damage (cytochrome oxidase, mitochondrial DNA) that were coupled to reductions in mitochondrial antioxidant capacity and copy number in vascular tissue compared to filtered air-exposed controls. Furthermore, basic histologic analysis suggested early atherosclerotic changes in smoke exposed aortas. These findings may be of significance in explaining the potential for increased atherosclerotic disease susceptibility in adulthood following early life smoke exposure because inflammation and mitochondrial damage and dysfunction in response to tobacco smoke exposure are features of early atherosclerosis.

In conclusion, our study demonstrates that prenatal and postnatal maternal exposure to environmental tobacco smoke increases neonatal arterial expression of genes that are pro-inflammatory and induce or contribute to vascular injury while reducing the arterial expression of a gene for angiogenesis. These observations have not been previously reported and provide a molecular explanation for early deleterious effects of ETS on the vasculature that relates to at least two vascular physiologic processes: activation of a pro-inflammatory gene cascade and inhibition of vascular repair to injury via inhibition of angiogenic genetic control. Further studies are needed to determine if the arterial injury and activation observed in neonatal vessels in response to ETS exposure will translate into increased susceptibility to vascular disease later in life.
Acknowledgements The authors would like to acknowledge the assistance of the Center for Health and the Environment and the technical assistance of Kristine Lewis at the University of California, Davis in the performance of these studies. This work was also made possible by the Frances Lazda endowment in Women's Cardiovascular Medicine to AV. JR was supported by an NIH R01 (HL55667) and the Richard A. and Nora Eccles Harrison endowed chair in Diabetes Research. These studies were also supported by grants from the National Institutes of Health (ES00628, ES011634, ES05707 and P51 RR00169).

Open Access This article is distributed under the terms of the Creative Commons Attribution Noncommercial License which permits any noncommercial use, distribution, and reproduction in any medium, provided the original author(s) and source are credited.

\section{References}

1. Barber, K., Mussin, E., \& Taylor, D. K. (1996). Fetal exposure to involuntary maternal smoking and childhood respiratory disease. Annals of Allergy, Asthma \& Immunology, 76(5), 427-430.

2. Dybing, E., \& Sanner, T. (1999). Passive smoking, sudden infant death syndrome (SIDS) and childhood infections. Human \& Experimental Toxicology, 18(4), 202-205.

3. Hanke, W., Sobala, W., \& Kalinka, J. (2004). Environmental tobacco smoke exposure among pregnant women: impact on fetal biometry at 20-24 weeks of gestation and newborn child's birth weight. International Archives of Occupational and Environmental Health, 77(1), 47-52.

4. Hutchison, S. J., et al. (1998). In utero and neonatal exposure to secondhand smoke causes vascular dysfunction in newborn rats. Journal of the American College of Cardiology, 32(5), 14631467.

5. Ji, C. M., et al. (1998). Maternal exposure to environmental tobacco smoke alters Clara cell secretory protein expression in fetal rat lung. The American Journal of Physiology, 275(5 Pt 1), L870-L876.

6. Joad, J. P., et al. (1999). Perinatal exposure to aged and diluted sidestream cigarette smoke produces airway hyperresponsiveness in older rats. Toxicology and Applied Pharmacology, 155(3), 253260.

7. Lee, C. Z., et al. (2000). Effect of in utero and postnatal exposure to environmental tobacco smoke on the developmental expression of pulmonary cytochrome P450 monooxygenases. Journal of Biochemical and Molecular Toxicology, 14(3), 121-130.

8. Milner, A. D., et al. (1999). Effects of smoking in pregnancy on neonatal lung function. Archives of Disease in Childhood. Fetal and Neonatal Edition, 80(1), F8-F14.

9. Nelson, E., et al. (1999). Maternal passive smoking during pregnancy and foetal developmental toxicity. Part 2: histological changes. Human \& Experimental Toxicology, 18(4), 257-264.

10. Obwegeser, R., et al. (1999). Maternal cigarette smoking increases F2-isoprostanes and reduces prostacyclin and nitric oxide in umbilical vessels. Prostaglandins \& Other Lipid Mediators, 57 (4), 269-279.

11. Oncken, C. A., et al. (2003). Effect of maternal smoking on fetal catecholamine concentrations at birth. Pediatric Research, 53(1), $119-124$.

12. Windsor, R. (2003). Smoking cessation or reduction in pregnancy treatment methods: a meta-evaluation of the impact of dissemination. The American Journal of the Medical Sciences, 326(4), 216-222.

13. Matturri, L., et al. (2003). Intimal preatherosclerotic thickening of the coronary arteries in human fetuses of smoker mothers. Journal of Thrombosis and Haemostasis, 1(10), 2234-2238. 
14. Berenson, G. S., \& Srinivasan, S. R. (1999). Prevention of atherosclerosis in childhood. Lancet, 354(9186), 1223-1224.

15. Raitakari, O. T., et al. (2003). Cardiovascular risk factors in childhood and carotid artery intima-media thickness in adulthood: the Cardiovascular Risk in Young Finns Study. Jama, 290(17), 2277-2283.

16. Knoflach, M., et al. (2003). Cardiovascular risk factors and atherosclerosis in young males: ARMY study (Atherosclerosis Risk-Factors in Male Youngsters). Circulation, 108(9), 1064-1069.

17. Williams, C. L., et al. (2002). Cardiovascular health in childhood: a statement for health professionals from the Committee on Atherosclerosis, Hypertension, and Obesity in the Young (AHOY) of the Council on Cardiovascular Disease in the Young, American Heart Association. Circulation, 106(1), 143-160.

18. Zieske, A. W., Malcom, G. T., \& Strong, J. P. (2002). Natural history and risk factors of atherosclerosis in children and youth: the PDAY study. Pediatric Pathology \& Molecular Medicine, 21 (2), 213-237.

19. Pope, C. A., 3rd, et al. (2004). Cardiovascular mortality and longterm exposure to particulate air pollution: epidemiological evidence of general pathophysiological pathways of disease. Circulation, 109(1), 71-77.

20. Mullick, A. E., et al. (2002). Reactive carbonyls from tobacco smoke increase arterial endothelial layer injury. American Journal of Physiology. Heart and Circulatory Physiology, 283(2), H591H597.

21. Roberts, K. A., et al. (1996). Effect of environmental tobacco smoke on LDL accumulation in the artery wall. Circulation, 94 (9), 2248-2253.

22. Taub, D. D., \& Oppenheim, J. J. (1994). Chemokines, inflammation and the immune system. Therapeutic Immunology, 1(4), 229-246.

23. Ross, R. (1999). Atherosclerosis is an inflammatory disease. American Heart Journal, $138(5$ Pt 2), S419-S420.

24. Ross, R., \& Glomset, J. A. (1973). Atherosclerosis and the arterial smooth muscle cell: proliferation of smooth muscle is a key event in the genesis of the lesions of atherosclerosis. Science, 180(93), $1332-1339$.

25. Libby, P. (2006). Inflammation and cardiovascular disease mechanisms. The American Journal of Clinical Nutrition, 83(2), 456S-460S.

26. Vasankari, T., et al. (2001). Oxidized LDL and thickness of carotid intima-media are associated with coronary atherosclerosis in middle-aged men: lower levels of oxidized LDL with statin therapy. Atherosclerosis, 155(2), 403-412.

27. Weber, C., Schober, A., \& Zernecke, A. (2004). Chemokines: key regulators of mononuclear cell recruitment in atherosclerotic vascular disease. Arteriosclerosis, Thrombosis, and Vascular Biology, 24(11), 1997-2008.
28. Ramos, M. A., et al. (1998). Induction of macrophage VEGF in response to oxidized LDL and VEGF accumulation in human atherosclerotic lesions. Arteriosclerosis, Thrombosis, and Vascular Biology, 18(7), 1188-1196.

29. Appay, V., \& Rowland-Jones, S. L. (2001). RANTES: a versatile and controversial chemokine. Trends in Immunology, 22(2), 83-87.

30. Conti, P., \& DiGioacchino, M. (2001). MCP-1 and RANTES are mediators of acute and chronic inflammation. Allergy and Asthma Proceedings, 22(3), 133-137.

31. Lloyd, C. M., et al. (1997). Role of MCP-1 and RANTES in inflammation and progression to fibrosis during murine crescentic nephritis. Journal of Leukocyte Biology, 62(5), 676-680.

32. Krishnaswamy, G., et al. (1999). Human endothelium as a source of multifunctional cytokines: molecular regulation and possible role in human disease. Journal of Interferon \& Cytokine Research, 19(2), 91-104.

33. Galkina, E., \& Ley, K. (2007). Vascular adhesion molecules in atherosclerosis. Arteriosclerosis, Thrombosis, and Vascular Biology, 27(11), 2292-2301.

34. Springer, T. A. (1990). Adhesion receptors of the immune system. Nature, 346(6283), 425-434.

35. Watanabe, T., \& Fan, J. (1998). Atherosclerosis and inflammation mononuclear cell recruitment and adhesion molecules with reference to the implication of ICAM-1/LFA-1 pathway in atherogenesis. International Journal of Cardiology, Suppl 66(1), S45-S53. discussion S55.

36. Celletti, F. L., et al. (2001). Vascular endothelial growth factor enhances atherosclerotic plaque progression. Natural Medicines, 7 (4), 425-429.

37. Virmani, R., et al. (2005). Atherosclerotic plaque progression and vulnerability to rupture: angiogenesis as a source of intraplaque hemorrhage. Arteriosclerosis, Thrombosis, and Vascular Biology, 25(10), 2054-2061.

38. Burke, P. A., Lehmann-Bruinsma, K., \& Powell, J. S. (1995). Vascular endothelial growth factor causes endothelial proliferation after vascular injury. Biochemical and Biophysical Research Communications, 207(1), 348-354.

39. Gill, M., et al. (2001). Vascular trauma induces rapid but transient mobilization of VEGFR2(+)AC133(+) endothelial precursor cells. Circulation Research, 88(2), 167-174.

40. Ray, P. S., \& Fox, P. L. (2007). A post-transcriptional pathway represses monocyte VEGF-A expression and angiogenic activity. The EMBO Journal, 26(14), 3360-3372.

41. Westbrook, D., Anderson, P., Pinkerton, K., \& Ballinger, S. (2010). Perinatal tobacco smoke exposure increases vascular oxidative stress and mitochondrial damage in non-human primates. Cardiovascular Toxicology, 10(3), 216-226. 